\title{
Mobilidade E Pandemia: Análise Da Vulnerabilidade Dos Refugiados Diante Da Covid-19 No Nordeste Brasileiro
}

\author{
Arnelle Rolim Peixoto * \\ Universidade de Salamanca, Salamanca, Espanha. \\ iD https://orcid.org/0000-0002-6173-218X \\ Kananda Beatriz Pinto de Sena ** \\ Universidade Estadual do Ceará, Programa de Pós-Graduação em Georgrafia, Fortaleza-CE, Brasil. \\ iD https://orcid.org/0000-0002-8468-669X \\ Camilla Martins Cavalcanti \\ Universidade de Fortaleza, Programa de Pós-Graduação em Direito, Fortaleza-CE, Brasil.
} iD https://orcid.org/oooo-0002-9241-8687

Resumo: Na pandemia da COVID-19, são muitos os desafios referentes aos fluxos de mobilidade humana. Nesse sentido, objetiva-se analisar mobilidade internacional de refugiados no nordeste brasileiro diante da pandemia e a possível acentuação da vulnerabilidade dos sujeitos migrantes frente a esta conjuntura. O artigo está estruturado em três etapas. Inicialmente, mostrou-se o aparato (nacional e internacional) protetivo referente aos refugiados. Em seguida, analisou-se o desafio do acolhimento dos refugiados e a possibilidade da caracterização acentuada da vulnerabilidade destes por causa da pandemia da COVID-19, e, para tanto, foram utilizados dados do Ministério da Justiça, em especial do Comitê Nacional para os Refugiados (CONARE), do Alto Comissariado das Nações Unidas para os refugiados (ACNUR), e também do Ministério da Saúde. Por fim, é explicada a necessidade de instrumentos/meios que garantam a proteção de refugiados em situações agravadoras de risco, especialmente, diante dos fatos e das consequências da pandemia da COVID-19. A pesquisa usou a metodologia do tipo bibliográfica, de natureza qualitativa, com fins descritivos e exploratórios. Concluiu-se que a pandemia da COVID-19 é elemento configurador da dupla vulnerabilidade da população em situação de refúgio, e, assim, tem-se a emergência de novos marcos regulatórios e de instrumentos que possibilitem a proteção dos refugiados.

Palavras chave: Refúgio. Coronavírus. Região Nordeste do Brasil.

* Pós-doutoranda em Direitos Sociais pela Universidade de Salamanca- Espanha (2018). Doutorado em Direito pela Universidade de Salamanca- Espanha. Professora do Grupo de Estudos em Direito e Assuntos Internacionais (GEDAI-UFC-DIREITO). Professora da Faculdade Stella Maris. Email: arnellerolim@hotmail.com

** Mestranda no Programa de Pós-Graduação em Geografia (ProPGeo/UECE). E-mail: beatriz.kan@hotmail.com

**** Mestranda em Direito Constitucional pela Universidade de Fortaleza (UNIFOR). E-mail: camillam.cavalcanti@outlook.com

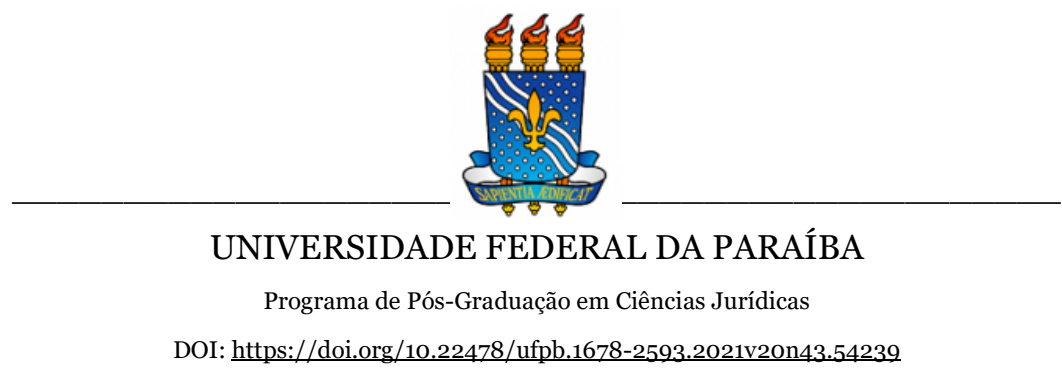




\title{
Mobilidade E Pandemia: Análise Da Vulnerabilidade Dos Refugiados Diante Da Covid-19 No Nordeste Brasileiro
}

\author{
Arnelle Rolim Peixoto ${ }^{1}$
}

Kananda Beatriz Pinto de Sena²

\author{
Camilla Martins Cavalcanti
}

\section{INTRODUÇÃO}

No período atual, compreende-se que a COVID-19, doença causada pelo novo coronavírus, foi considerada uma pandemia, devido as suas consequências ocorrerem como uma epidemia 3 em ampla área geográfica, chegando a um nível mundial. Ademais, concomitante à pandemia, tem-se as dinâmicas da mobilidade internacional, que são ocasionadas por distintos motivos, a exemplo de guerras e conflitos armados que ainda estão ocorrendo em muitas regiões na escala global, bem como, outros motivos ensejadores de refúgio, como a perseguição por raça, política e religião, ou, até mesmo, por grave violação aos direitos humanos, motivo acrescentado pela declaração de Cartagena em 1984.

Destarte, o texto tem como objetivo a discussão teórica da acentuação da vulnerabilidade dos refugiados diante da pandemia da

\footnotetext{
${ }^{1}$ Bolsista de Pós-Doutorado Universidade de Salamanca.

${ }^{2} \mathrm{O}$ presente trabalho foi realizado com apoio do Conselho Nacional de Desenvolvimento Científico e Tecnológico (CNPq)

3 A Organização mundial da Saúde (OMS) define como epidemia a ocorrência de casos de doenças, comportamento específico associado com a saúde, ou eventos relacionados com a saúde além do que seria esperado normalmente.
} 
COVID-19 no Nordeste brasileiro, e está dividido em duas partes centrais: na primeira, destaca-se a possibilidade da acentuação da vulnerabilidade dos refugiados diante da pandemia da COVID-19, considerando a legislação nacional e internacional. Já na segunda, apresenta-se o recente fluxo de refugiados e a pandemia na região nordeste do Brasil.

Nesse sentido, no que diz respeito ao amparo legal para proteção dos refugiados, este pode ser encontrado tanto na legislação nacional quanto na internacional, seja pela Convenção de 1951 ou pela Lei $n^{0}$. 9474/97, além de alguns princípios da política migratória estabelecida pela atual Lei de Migração, que podem servir de base para serem usados no contexto de refúgio. Essa interligação é importante para o aporte da proteção dos refugiados em tempos de pandemia haja vista as vulnerabilidades desse grupo especifico que são acentuadas nesse período pandêmico.

No que se refere aos dados, são utilizadas as informações do Alto Comissariado das Nações Unidas para os Refugiados (ACNUR) e do Comitê Nacional para os Refugiados (CONARE) para mostrar o quantitativo e a origem da população que solicitou refúgio no Nordeste do Brasil; além disso, foram coletados os dados do Ministério da Saúde para evidenciar os casos de COVID-19 na região Nordeste do país. Ainda, cabe pontuar que, os dados foram coletados no período de março, abril, maio, junho e julho de 2020.

Em relação aos procedimentos metodológicos, a pesquisa é bibliográfica e documental, realizada por meio de livros, artigos científicos, dados oficiais e informações da Organização das Nações Unidas (ONU), da Organização Pan-americana de Saúde (OPAS), da Organização Mundial de Saúde (OMS) e da Agência da ONU para refugiados (ACNUR). O método utilizado é o dedutivo e a abordagem é exploratória e qualitativa.

Com os resultados deste estudo e com a sua publicação, pretende-se contribuir com a temática dos refugiados nestas primeiras décadas do século XXI, pois serão apresentadas questões referentes aos direitos humanos e à vulnerabilidade social desta população, que 
são de interesse global. Além disso, a proteção a esse grupo de minorias também pode ser configurada como uma proteção mundial, no que diz respeito a evitar a disseminação do novo coronavírus no mundo.

\section{A SITUAÇÃO DOS REFUGIADOS FRENTE A PANDEMIA DA COVID-19}

Quando se fala em refugiados, são inegáveis as perspectivas em relação à proteção e à prevenção dos seus direitos, já que são grupos desprotegidos, que fogem do seu país por motivo de perseguição e que estão propensos a diversos tipos de vulnerações no percurso da sua mobilidade e no país de chegada. Diante disso, um viés do Direito Internacional buscou se preocupar com a elaboração de instrumentos e de organismos para a proteção, no âmbito internacional, direcionado especificamente a esse grupo. Como resultado dessa instrumentalização na proteção dos direitos dos refugiados, o Brasil incorporou em âmbito interno essa norma internacional, como também adaptou as normas nacionais relacionadas diretamente ou indiretamente com a temática do refúgio.

Entretanto, mesmo com todas as garantias estabelecidas em normativos, os refugiados ainda encontram diversas dificuldades, desde a integração ao país de origem, a falta de conscientização ou de conhecimento de determinada parte da população e de órgãos públicos - que podem dificultar os trâmites de documentação para esses refugiados -, até a mudança nas políticas migratórias, principalmente quando o país decide por fechar suas fronteiras sob a desculpa da segurança nacional, da crise econômica ou mesmo de questões de saúde, como é o caso vivenciado atualmente. A pandemia vem afetando todos os países, principalmente os grupos mais vulneráveis, em condição de precariedade, estando entre estes os refugiados, 
acentuando-se ainda mais essa condição diante da pandemia da COVID-19.

\subsection{O Aparato Internacional Protetivo Referente Aos Refugiados}

Nas dimensões dos Direitos Humanos, vale destacar a noção de que não são de outros. São nossos, coletivos e indivisíveis. Abarcam e estão vinculados às alteridades étnicas, raciais, territoriais e de gênero. Assim sendo, exigem uma leitura crítica do atual estágio da crise estrutural do capital e também do papel do Estado na modernidade - a estatalidade (KURZ, 2010).

O período subsequente a Segunda Guerra Mundial foi marcado pelas recomendações internacionais nos sistemas protetivos globais e regionais com relação aos Direitos Humanos (MACENA et.al., 2019, p.2-3). Nesse sentido, a normatização da proteção dos refugiados a nível internacional se deu a partir da preocupação em resolver a questão dos refugiados na Europa após a Segunda Guerra.

Além disso, foi estabelecida a Convenção Relativa ao Estatuto dos Refugiados, adotada em 28 de julho de 1951 (ACNUR, 1951), instrumento específico de proteção aos direitos dos refugiados e que trabalha a definição do instituto, facilitando a identificação desse grupo específico dentro do contexto complexo da mobilidade humana. A definição dessa Convenção foi ampliada pelo Protocolo sobre o Estatuto dos Refugiados em 1967, de forma a abranger não só os refugiados no contexto da Europa, mas também estabelecendo uma definição mais expandida, transcendendo as questões territoriais e temporais da Convenção de 1951 (RAMOS, 2011).

No contexto internacional, de acordo com o artigo $1^{\mathrm{o}}$ do Estatuto, refugiado é definido como sendo aquela pessoa que

[...] temendo ser perseguida por motivos de raça, religião, nacionalidade, grupo social ou opiniões políticas, se encontra fora do país de sua nacionalidade, grupo social ou opiniões políticas, se encontra fora do país de sua nacionalidade e que não pode ou, em virtude desse temor, 
não quer valer-se da proteção desse país [...] (ACNUR, 1951).

Dentre os direitos estabelecidos no Estatuto, o que se refere à relação entre o refugiado e o Estado que o recebe, existe um essencial, estabelecido no artigo 33 do Estatuto: o princípio do non-refoulement, ou seja, a proibição da não devolução, não podendo o Estado expulsar o refugiado para o seu país de origem. Com isso, é estabelecida a eles uma garantia primordial, principalmente em momentos em que os contextos político, econômico e social facilitam para criar ou fortalecer discursos nacionalistas de cunho xenófobo contra os refugiados.

Conjuntamente a essa normatização, foi instituído um órgão próprio para assegurar a proteção dos refugiados e o cumprimento dos instrumentos internacionais, surgindo assim o Alto Comissariado das Nações Unidas para Refugiados (ACNUR, 2020), através da Resolução da Assembleia Geral das Nações Unidas. Criada inicialmente para auxiliar os refugiados europeus, o seu objetivo foi ampliado juntamente com o Protocolo do Estatuto, e seu mandato passou a englobar a todos os refugiados de maneira geral, tornando-se uma agência com mandato fixo direcionada à proteção dos refugiados, como também para proteção dos apátridas (ACNUR, 2020). Essa agência ocupa um papel importante na assistência às diversas crises migratórias, sobretudo nos campos de refugiados, que, por sua vez, vivem as mais diversas situações de vulnerações, principalmente mulheres e crianças.

$\mathrm{Na}$ legislação interna, o Brasil ratificou a Convenção Relativa ao Estatuto dos Refugiados em 1961 e o Protocolo do Estatuto em 1972, submetendo-se, portanto, ao aparato internacional relativo à proteção dos refugiados.

Apesar de ter ratificado esses instrumentos, no ano de 1997 foi editada a Lei $n^{0} .9 .474$, que passou a redefinir a proteção dos refugiados, inclusive de maneira mais ampla, abrangendo o seu conceito de acordo com o estabelecido na Declaração de Cartagena 1984, instrumento de recomendação regional no âmbito da América 
Latina. Esta inclui no conceito de refugiado, além daquele estabelecido no Estatuto, no artigo $1^{\mathrm{o}}$ inciso III da Lei, a causa de grave e generalizada violação de direitos humanos, com o qual o indivíduo é obrigado a deixar o seu país de nacionalidade e buscar refúgio em outro país (RAMOS, 2011).

Nesse sentido, ressalta-se que "somente com a Lei n ${ }^{0}$ 9.474, de 22 de julho de 1997, que o país estabelece um marco políticoadministrativo, regulamentando os mecanismos para a implementação do Estatuto" (RIBEIRO, 2017, p.237). Já que a legislação interna incluiu uma estrutura específica para o assunto de refúgio,

No que refere ao direito dos refugiados, o Brasil deu um passo muito importante, com a promulgação da Lei ${ }^{0}$ 9.474/97, com destaque para uma das mais avançadas legislações sobre o tema, especialmente por ter criado o Comitê Nacional para Refugiados (CONARE), órgão colegiado que cuida das solicitações de refúgio e que conseguiu consolidar uma estrutura que permitiu a participação da sociedade civil na análise desses pedidos (COSTA; PEIXOTO, 2018, p. 520)

Portanto, observa-se que a Lei 9.474/97 veio reforçar o reconhecimento dos direitos dos refugiados estabelecidos no Estatuto e no Protocolo, juntamente para desenhar uma estrutura institucional que trabalhe sobre a temática dentro de órgão institucional do governo.

Ademais, de toda a proteção estabelecida pelos instrumentos internacionais e replicada no âmbito interno de maneira mais abrangente - situando uma maior efetividade na proteção dos direitos dos refugiados -, cabe destacar a Lei de Migração, Lei n ${ }^{\circ}$ 13.445, de 2017, que, apesar de tratar sobre migrante, traz alguns princípios e diretrizes da política migratória, estabelecidos no artigo $3^{\circ}$, que podem ser interligados para uma maior proteção dos refugiados. Observa-se que alguns são de extrema importância, como, por exemplo, o inciso IV que, ao afirmar que "a não discriminação em razão dos critérios ou dos procedimentos pelos quais a pessoa foi admitida em território nacional”, reforça uma política de proteção para qualquer forma de mobilidade humana. 
Outros princípios e diretrizes estabelecidos na Lei de Migração são essenciais para proteger contra qualquer ingerência que possa acentuar ainda mais a vulnerabilidade dos refugiados. Dentre eles, destacam-se a não criminalização da migração e a acolhida humanitária, estabelecidos nos respectivos incisos III e VI do art. $3^{\mathrm{o}}$ da mencionada Lei.

Isto posto, observa-se que o Brasil vem gradativamente aproximando sua normatização interna dos parâmetros estabelecidos pelos instrumentos internacionais na proteção dos refugiados e pela igualdade preconizada no artigo $5^{\circ}$ da sua Constituição Federal (BRASIL, 1988). Dentro dessa perspectiva, cabe salientar:

Para se desincumbir a contento desses seus deveres, o Estado traça um planejamento de desenvolvimento, assim como estabelece ações e políticas públicas que atendam a todas as necessidades de seus cidadãos, desde aqueles que se tornaram tradicionais - posto que ao longo do Século XX tornaram-se objeto clássico de planejamento, a exemplo da saúde, da educação, da previdência social e da assistência social - quanto aqueles que o Estado pode estabelecer como medidas protetivas daquelas parcelas da população que carecem de maior resguardo (CECATO et.al, 2017, p.21).

Nesse sentido, é interessante destacar a importância da aplicação efetiva dessa proteção através de meios institucionais estatais, garantido a efetividade da proteção nos mais diversos contextos sociais, políticos, econômicos ou na crise sanitária mundial, haja vista a necessidade de conceder o amparo a todos, em especial, aos mais vulneráveis, como é o caso dos refugiados.

\subsection{A Possibilidade Da Acentuação Da Vulnerabilidade Dos Refugiados Diante Da Pandemia Da Covid-19}

No primeiro momento, cabe contextualizar que, no final de 2019, na cidade de Wuhan, na China, foi constatada a presença de uma doença causada pelo novo coronavírus, denominada de COVID-19. 
Segundo Dumont (2020), Wuhan é uma cidade ligada à China e ao mundo, e seu aeroporto apresentou no total 25 milhões de passageiros no período de 2018. Logo, pode-se estimar que mais de 3 milhões de pessoas passaram pelo aeroporto entre o começo da epidemia e o confinamento, operado em 23 de janeiro de 2020 (DUMONT, 2020, p. 4).

Além disso, o equivalente a 80\% das pessoas conseguiu se recuperar bem sem a necessidade de internação em hospitais; contudo, de cada seis pessoas contaminadas, uma tem dificuldade para respirar e, assim, precisa de atendimento em hospital. Apesar de existir um grupo de risco, composto por idosos e pessoas com algumas comorbidades, como pressão alta, doenças respiratórias ou cardíacas, diabetes e câncer, entende-se que qualquer pessoa, em qualquer idade, pode contrair a doença em seu nível grave (OPAS, 2020, p.12).

Na perspectiva de Filippo Grandi (2020, p.3, tradução nossa), o novo coronavírus resultou em uma lembrança para os indivíduos de que o mundo está conectado e, na medida que se compreende isso, também se capta que os países precisam se unir, sem menosprezar nenhum povo, para, de maneira concreta, solucionar o desafio mundial da pandemia.

Ademais, o autor Grandi (2020, p.3, tradução nossa) explana ainda que a pandemia testa os sistemas de saúde e a habilidade de atuação conjunta das nações, principalmente por se fazer necessário olhar para todos os cantos do planeta, inclusive os menos privilegiados, a fim de que concretamente se consiga ter a pandemia controlada. Nesse sentido, expõe especialmente a questão dos refugiados e da necessidade de apoio internacional, da seguinte forma:

Os migrantes e refugiados - independentemente de seu status formal - devem fazer parte integrante dos sistemas e planos nacionais de combate ao vírus. Muitas dessas mulheres, homens e crianças se encontram em locais onde os serviços de saúde estão sobrecarregados ou inacessíveis. Eles podem estar confinados a acampamentos e assentamentos, ou vivendo em favelas urbanas, onde a superlotação e o saneamento com poucos recursos aumentam o risco de exposição. $\mathrm{O}$ apoio 
internacional é urgentemente necessário para ajudar os países anfitriões a intensificar os serviços - tanto para migrantes quanto para as comunidades locais - e incluí-los nos acordos nacionais de vigilância, prevenção e resposta. Não fazer isso colocará em risco a saúde de todos - e o risco de aumentar a hostilidade e o estigma. Também é vital que qualquer restrição dos controles nas fronteiras, restrições de viagem ou limitações à liberdade de movimento não impeça as pessoas que podem estar fugindo da guerra ou perseguição de acessar a segurança e proteção (GRANDI, 2020, p.5).

O Alto Comissariado das Nações Unidas para os refugiados (ACNUR, 2020, p.2-7) enumera cinco fatos que refletem a importância de lembrar os refugiados em meio à pandemia da COVID 19: existem mais de 70 milhões de pessoas que não podem voltar para o seu país de origem; cerca de mais da metade dos refugiados do mundo se encontram em países que ainda estão na fase de desenvolvimento; os locais para receber refugiados já estão lotados; os idosos comportam o grupo de risco e há refugiados idosos; o coronavírus acontece paralelamente a conflitos armados mundiais.

\section{A Agência da ONU para Refugiados (ACNUR), a} Organização Internacional para Migração (OIM) e a Organização Mundial da Saúde (OMS), em consonância, emitiram uma nota relatando que $75 \%$ dos refugiados estão em países em desenvolvimento que têm os seus sistemas de saúde em situações complicadas; dessa forma, eles não estão preparados para uma crise como esta, e podem precisar de um apoio financeiro extra (AGÊNCIAS..., 2020, p.2-3).

Considera-se que os migrantes e refugiados atingem uma acentuação das suas vulnerabilidades com o novo coronavírus e, no cenário em que essas pessoas são incluídas no sistema de saúde, se tem, consequentemente, a efetiva melhora na própria saúde pública. $\mathrm{E}$ ainda se acrescenta que, mesmo com as fronteiras fechadas, têm-se mecanismos de se cumprir as regulamentações internacionais no que diz respeito aos refugiados (AGÊNCIAS..., 2020, p.4).

Na concepção de Ann Burton (ACNUR, 2020, p.4-5), dentre as aprendizagens do ACNUR com outras epidemias já ocorridas no mundo (como o EBOLA), observou-se, primeiramente, que se faz 
necessária uma preparação envolvendo a criação de planos do ACNUR ligados aos planos dos Estados locais, pois respostas locais são primordiais. Após, notou-se que o desenvolvimento de sistemas de laboratório e de vigilância foi fundamental. Por fim, aprendeu-se a essencialidade de monitorar a proteção aos refugiados, bem como, que as respostas interligadas dos países receptores também são de grande importância. Ann Burton (ACNUR, 2020, p.5) aduz que:

[...] as epidemias anteriores mostraram como é vital envolver os refugiados desde o primeiro dia, tanto para entender suas preocupações na resposta a surtos quanto para garantir que levemos em consideração as sensibilidades sociais e culturais. Sabemos o quanto é importante garantir a continuidade dos serviços de saúde prioritários para garantir que não haja aumento da mortalidade por outras condições [...]. (ACNUR, 2020, p.5).

No que diz respeito às ações tomadas pelo Alto Comissário Das Nações Unidas para os Refugiados frente à pandemia da COVID19. Ann Burton, que chefia a seção de saúde pública do ACNUR, acrescenta que se tem reserva de medicamentos e equipamentos de proteção individual (EPI) para os profissionais de saúde, e que são realizados seminários on-line com o viés de tratar das condições atuais da pandemia e de fornecer informações e orientações. Além disso, também estão monitorando as restrições ao recebimento de refugiados em detrimento da pandemia da COVID-19 (ACNUR, 2020, p. 6-8). Nesse sentido, relata que, além dos desafios relacionados à compra de medicamentos e de EPI diante da situação globalizada da pandemia, ainda se tem a luta para garantir que as fronteiras dos países não estejam fechadas para os refugiados e que tenham acesso à saúde (ACNUR, 2020, p.8).

Quanto às ações do Alto comissário das Nações Unidas (ACNUR, 2020, p.3) no Brasil, especificamente no período de pandemia, destacam-se a criação de um material para que refugiados tenham acesso às informações, a distribuição de acessórios básicos de higiene e proteção, ações coordenadas com a força tarefa e a operação acolhida, e o monitoramento da fronteira brasileira e dos aeroportos. 
Conforme a Lei $\mathrm{n}^{0}$ 13.982, de 2 de abril de 2020 (BRASIL, 2020), que concedeu o auxílio emergencial em razão da situação econômica do país em detrimento do isolamento social decorrente da pandemia da COVID-19, os migrantes também têm direito ao auxílio emergencial do governo federal (BRASIL, 2020). Porém, por não entenderam os sistemas burocráticos ou a língua, dentre outros fatores, ele tem mais dificuldades do que os brasileiros para solicitar e receber o auxílio devido. Assim, pode-se aduzir:

\begin{abstract}
Pensar políticas e intervenções de saúde global para enfrentar a pandemia de Covid-19 em contextos de extrema vulnerabilidade como o dos refugiados exige ir além de políticas públicas, intervenções e medidas de saúde pública de "tamanho único" e de cima para baixo, tão frequentes no campo da saúde global, que desconsideram as condições de vida dos indivíduos para os quais essas medidas são destinadas, e envolver esses grupos em seu desenho e implementação para garantir sua efetividade nesses contextos [...] (RODRIGUES; CAVALCANTE; FAERSTEIN, 2020, p. 9).
\end{abstract}

Dessa forma, entende-se a pandemia da COVID-19 como um elemento configurador da precariedade dos refugiados e, por isso, se tem a necessidade de assegurar instrumentos que garantam a proteção de refugiados em situações agravadoras de risco, especialmente durante a pandemia, como políticas públicas emergenciais e programadas em conjunto com o ACNUR.

\title{
3 A PANDEMIA E O RECENTE FLUXO DE REFUGIADOS: A REGIÃO NORDESTE DO BRASIL
}

Durante os últimos meses (março, abril, maio, junho, julho de 2020) tem-se visto uma série de estudos, análises e notícias que demonstram o quanto os povos são múltiplos e interconectados através do processo da globalização, e isso acarretou impactos ao redor do mundo, como demonstrado na proliferação da COVID-19. 
Com mais de 15 milhões de casos confirmados no mundo e mais de 600 mil mortes, a pandemia da COVID-19 impactou a economia, a sociedade e a política. Cerca 187 países e 200 territórios em todo o mundo já foram atingidos pelo novo coronavírus (SOUZA, 2020). No Brasil, até o presente momento (20 de julho de 2020), foram confirmados 2 milhões de casos de COVID-19; já na região nordeste do país, há aproximadamente 769 mil casos confirmados e 26 mil óbitos, conforme a tabela 1.

Tabela 1 - Número de casos e óbitos (COVID-19), no nordeste do Brasil (27/03/2020 a 24/07/2020)

\begin{tabular}{lcc}
\hline UF & $\begin{array}{c}\text { Número de casos (COVID- } \\
\mathbf{1 9 )}\end{array}$ & Número de óbitos \\
\hline BA & 142767 & 3096 \\
CE & 158824 & 7426 \\
SE & 51132 & 1284 \\
PB & 74550 & 1653 \\
MA & 112683 & 2871 \\
PI & 44349 & 1215 \\
PE & 85042 & 6237 \\
RN & 46683 & 1666 \\
AL & 53713 & 1471 \\
TOTAL & 769743 & $\mathbf{2 6 9 1 9}$ \\
\hline
\end{tabular}

Fonte: Elaborado pelas autoras, com base nos dados do Ministério da saúde (2020).

De acordo com a tabela 1 , constata-se um grande número de casos da COVID-19 no Nordeste, sendo esses valores referentes ao período compreendido entre 27 de março e 24 de julho de 2020. Além disso, são notórios os estados que se destacam na quantidade de casos confirmados e também no número de óbitos, quais sejam: Ceará (158 mil casos e 7 mil óbitos), Bahia (142 mil casos e 3 mil óbitos), Maranhão (112 mil casos e 2 mil óbitos), Pernambuco (85 mil casos e 6 mil óbitos) e a Paraíba (74 mil casos e 1 mil óbitos).

Através dos dados do Ministério da Saúde, observa-se que a crise gerada pela pandemia revela as desigualdades regionais, percebidas, sobretudo, no Nordeste, que são inerentes ao sistema 
capitalista e expõem os diversos grupos sociais que estão sendo atingidos e os tornam vulneráveis aos efeitos da crise. Entre estes, estão refugiados e migrantes que encontram mais dificuldades em razão da instabilidade causada pela pandemia.

Nesse contexto, é válido salientar os dados sobre refúgio no mundo, no Brasil e Nordeste, para demostrar a fluidez da mobilidade antes e durante a pandemia. De acordo com o relatório do ACNUR “Tendências Globais 2019", em torno de 79,5 milhões de pessoas estavam deslocadas à força no final do ano de 2019, destas, 29,6 milhões estavam reconhecidas como refugiadas em outros países e, além disso, tem-se que 4,2 milhões esperavam serem reconhecidas formalmente como refugiadas (ACNUR, 2020).

No território brasileiro, aproximadamente 43 mil pessoas estão reconhecidas como refugiadas, de acordo com o Ministério da Justiça, por meio de dados levantados pelo Comitê Nacional para os Refugiados (CONARE), e 193 mil estão solicitantes de refúgio. Ao levar em consideração a escala do país, as regiões Sudeste e Norte são as que mais recebem e acolhem os refugiados; no entanto, a região Nordeste apresenta fluxos recentes de refugiados que merecem ser analisados, até para que seja possível identificar a realidade dessa população no contexto da pandemia. Nesse sentido, evidencia-se a quantidade de solicitações de refúgio, no Nordeste (por unidade federativa), no período de 2015-2019 (gráfico 1).

\section{Gráfico 1 - Estados do Nordeste com solicitação de refúgio (2015-2019)}




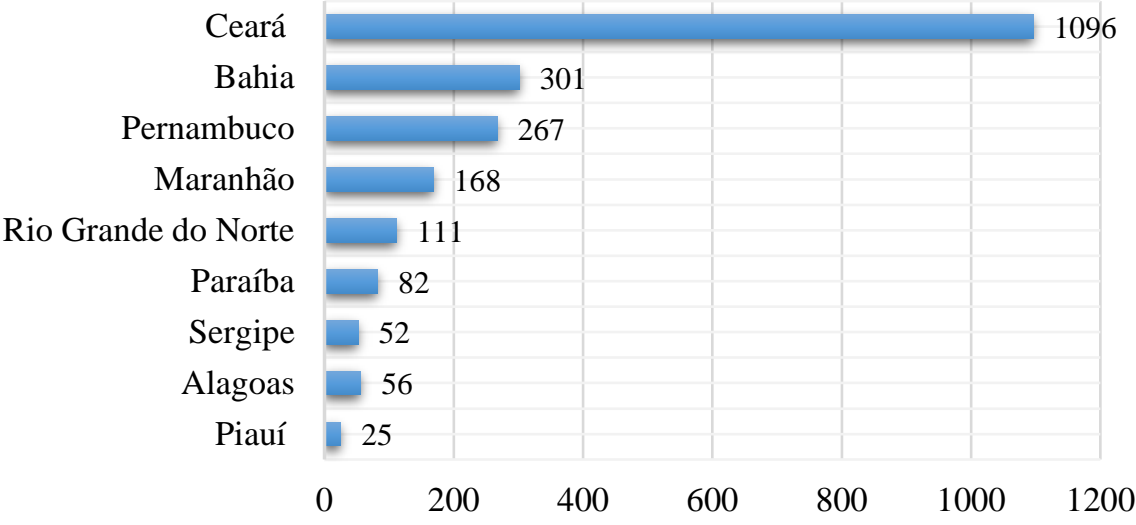

Fonte: Elaborado pelas autoras, com base nos dados do Comitê Nacional para Refugiados (CONARE).

De acordo com os dados do gráfico 1, verifica-se que foram registradas 2158 solicitações de refúgio no Nordeste do Brasil, estando a maioria delas concentradas no Ceará (1096 pedidos de refúgio), Bahia (301 pedidos de refúgio), Pernambuco (267 pedidos de refúgio), Maranhão (168 pedidos de refúgio) e Rio Grande Norte (111 pedidos de refúgio). Em menor número, há os estados de Paraíba (82 pedidos de refúgio), Sergipe (52 pedidos de refúgio), Alagoas (56 pedidos de refúgio) e, por último, o Piauí (25 pedidos de refúgio).

Além disso, a partir desses dados, é importante evidenciar a origem da população que solicitou refúgio na região Nordeste (no mesmo período temporal de 2015-2019), a saber: Cuba (730 pedidos de refúgio), Venezuela (661 pedidos de refúgio), Guiné-Bissau (343 pedidos de refúgio), Senegal (72 pedidos de refúgio), Haiti (32 pedidos de refúgio), China (30 pedidos de refúgio) Filipinas (30 pedidos de refúgio), Bangladesh (26 pedidos de refúgio), Angola (24 pedidos de refúgio), dentre outros países, conforme a tabela seguinte (Tabela 2).

Tabela 2 - Os principais países que solicitaram refúgio no Nordeste (2015-2019) 
Mobilidade E Pandemia: Análise Da Vulnerabilidade Dos Refugiados Diante Da...

\begin{tabular}{c|c}
\hline País de origem & $\begin{array}{c}\text { Número de } \\
\text { solicitações }\end{array}$ \\
\hline Cuba & 730 \\
\hline Venezuela & 661 \\
\hline Guiné-Bissau & 343 \\
\hline Senegal & 72 \\
\hline Haiti & 32 \\
\hline China & 30 \\
\hline Filipinas & 30 \\
\hline Bangladesh & 26 \\
\hline Angola & 24 \\
\hline Iraque & 23 \\
\hline Cabo Verde & 14 \\
\hline Nigéria & 13 \\
\hline Síria & 12 \\
\hline Colômbia & 10 \\
\hline Paquistão & 10 \\
\hline Gana & 9 \\
\hline El Salvador & 7 \\
\hline Moçambique & 7 \\
\hline Tunísia & 6 \\
\hline Argentina & 5 \\
\hline Congo & 5 \\
\hline Egito & 5 \\
\hline Afeganistão & 4 \\
\hline Benin & 4 \\
\hline Outros países4 & $\mathbf{7 6}$
\end{tabular}

Fonte: Elaborado pelas autoras, com base nos dados do Comitê Nacional para Refugiados (CONARE).

Ainda conforme a tabela 2, pode-se inferir que os principais fluxos de refugiados no Nordeste do Brasil são, sobretudo, da América Latina, África e Ásia, que são áreas geográficas do globo que tradicionalmente costumam realizar mobilidade internacional para distintos países e territórios. Para tanto, no recorte temporal mais recente (2020)5, de acordo com os dados do CONARE, identifica-se uma diminuição na quantidade de solicitações de refúgio em todo

4 Ressalte-se que existe também a solicitação de refúgio de outros países, porém em menor quantidade, e por isso estes foram agrupados. São eles: Itália, Líbano, Peru, República democrática do congo, Espanha, Estados Unidos, Gâmbia, Guiné, Marrocos, Portugal, Rússia, Serra Leoa, Turquia, França, Índia, Palestina, Togo, Uruguai, Alemanha, Arábia Saudita, Argélia, Bélgica, Camarões, Chile, Costa do Marfim, Equador, Guatemala, Israel, Mali, Maurício, Mauritânia, México, Polônia, Reino Unido, República Dominicana, República Tcheca, Suécia Suíça, e Tanzânia. 5 Os dados disponíveis sobre refúgio no ano 2020 são referentes aos meses de janeiro até maio. 
território brasileiro, tendo sido a queda ainda maior nos últimos três meses (março, abril e maio). No Nordeste, no período de janeiro a maio de 2020, houve apenas 89 solicitações de refúgio, dos seguintes países: Cuba (47 pedidos de refúgio), Venezuela (30 pedidos de refúgio), Guiné-Bissau (6 pedidos de refúgio), Senegal (1 pedidos de refúgio), Angola (1 pedido de refúgio), entre outros países.

A diminuição do fluxo de refugiados acontece desde 26 de março de 2020 (SOUSA, 2020), quando o governo brasileiro adotou a Portaria $\mathrm{N}^{\mathrm{O}} 47$, que proibia a entrada de migrantes no país pelo período 30 dias em razão do início da pandemia (BRASIL, 2020). Este decreto foi renovado em abril, no qual essa proibição se estendeu até 22 de maio de 2020, nessa oportunidade o governo publicou outra Portaria, de $\mathrm{n}^{0} 255$, com o intuito de manter a proibição de entrada de migrantes no território brasileiro (BRASIL, 2020). O documento proíbe a entrada de qualquer migrante no país, seja por terra, ar ou água. Assim, muitos refugiados ficaram impossibilitados de entrar pela fronteira brasileira; no entanto, a mobilidade da população dentro da escala do país permaneceu.

Segundo as informações do documento "Preparação, prevenção e controle da doença do coronavírus (COVID-19) para refugiados e migrantes em ambientes fora dos campos de refugiados", os refugiados vivenciam as seguintes situações:

\begin{abstract}
A maioria dos refugiados e migrantes vivem em acomodações individuais e comunitárias em cidades, áreas urbanas e industriais. Eles enfrentam ameaças à saúde pela COVID-19 semelhantes às enfrentadas pelas populações locais. No entanto, devido às condições de suas jornadas migratórias, oportunidades de emprego limitadas, precárias condições de moradia e trabalho, superlotação e acesso inadequado à alimentação, água, saneamento e outros serviços básicos, pessoas refugiadas e migrantes podem ter vulnerabilidades específicas [...] (OPAS, 2020, p.1).
\end{abstract}

A partir do exposto, corrobora-se com a discussão levantada no texto de que a pandemia acentua as desigualdades e a condição precária dos refugiados no território brasileiro. Ademais, é válido destacar que várias organizações internacionais, como o Alto Comissariado das Nações Unidas para os Refugiados, a Organização 
Internacional para As migrações (OIM) e a Organização Mundial da Saúde (OMS) chamaram atenção e tomaram providências no sentido de proteger os migrantes e refugiados da contaminação do coronavírus (COVID-19); no entanto, também é dever do Estado apresentar políticas efetivas em escalas nacional, regional e local, para proteger os sujeitos sociais que precisam de amparo legal.

Embora essa pandemia esteja em andamento, já existem alguns estudos e informações jornalísticas sobre como refugiados e imigrantes são afetados pela pandemia. Conforme informações coletadas no dia 21/04/2020 na Rádio jornal de Recife (PE), "Venezuelanos refugiados no Recife relatam falta de doações na pandemia”. Carvalho (2020) ressalta que:

[...] Sem a entrega de cestas básicas, os venezuelanos afirmam que já encontram dificuldade para conseguir fazer as refeiçõ̃es. Só no Bairro da Boa Vista, no Centro, existem pelo menos dois imóveis que servem de abrigo para os refugiados. Em um deles moram 28 pessoas, incluindo adultos e crianças. Se já não bastasse a fome, as famílias que vieram da Venezuela de ônibus ainda temem a contaminação. [...] Elas vivem aglomeradas em cômodos pequenos e sem condições adequadas de higiene. Uma água escura é a única que os refugiados contam para conseguir lavar as mãos. "Somos cinco famílias. O coronavírus que anda por aí pode pegar em uma criança e pode também pegar em todos aqui”, afirmou o autônomo Antônio Guanda (CARVALHO, 2020).

Ademais, há também outras informações sobre a situação dos refugiados que moram na Paraíba. Desde o início deste ano, pelo menos 40 indígenas venezuelanos da etnia warao foram diagnosticados com COVID-19. Através das informações e de dados encontrados, foi possível visualizar o quanto crise da pandemia afeta os refugiados, tanto do ponto de vista econômico e social, quando na esfera da vida, para a própria sobrevivência.

\section{CONSIDERAÇÕES FINAIS}


O presente trabalho teve por objetivo fazer a leitura e análise da mobilidade e da pandemia, com ênfase na vulnerabilidade dos refugiados situados no Nordeste do Brasil. Para isso, debruçou-se em entender o novo fenômeno da pandemia, que ainda está em curso e na quantidade de solicitações de refúgio para a região Nordeste.

Assim, para abordar o recorte do curso da pandemia no nordeste brasileiro, primeiramente, foi exposto todo o reduto legislativo referente ao Direito dos Refugiados no âmbito nacional e internacional. Depois, notou-se que a condição de vulnerabilidade dos refugiados foi acentuada em detrimento da pandemia da COVID-19. E, por fim, por meio de uma análise dos dados de pedidos de solicitação de refúgio (de 2015 a 2020) e dos referentes à pandemia, ambos no Nordeste, comprovam-se os pressupostos.

No que se refere aos dados apresentados durante o texto, analisou-se que a pandemia carrega múltiplas marcas da desigualdade social e que, sobretudo, amplia a vulnerabilidades dos diversos grupos sociais, com ênfase para a população que realiza mobilidade internacional, como é caso dos migrantes e refugiados. Ademais, percebe-se um aumento do número de solicitações de refúgio no Nordeste nos últimos anos; todavia, com a pandemia e fechamento das fronteiras do país, houve um decréscimo no número de pedidos de refúgio, na escala do território nação.

De acordo com a tabela 1, em um primeiro momento, identificaram-se, no período de março a julho de 2020, os impactos da pandemia da COVID-19 latentes no Nordeste do Brasil, com o equivalente a 769 mil casos confirmados e 26 mil óbitos. Após, foi observado que os estados da região nordeste que tiveram uma quantidade de casos e óbitos mais elevadas foram, na seguinte ordem, Ceará (158 mil casos e 7 mil óbitos), Bahia (142 mil casos e 3 mil óbitos), Maranhão (112 mil casos e 2 mil óbitos), Pernambuco (85 mil casos e 6 mil óbitos) e a Paraíba (74 mil casos e 1 óbitos).

Com relação à quantidade de solicitações de refúgio, constatou-se que foram registradas no Nordeste, entre os anos de 2015 
e 2020, 2.158 solicitações. Dentre essas, os estados que comportam mais solicitações da região são Ceará, Bahia, Pernambuco, Maranhão e Rio Grande Norte. Em proporções menores, se tem também a presença das solicitações nos seguintes estados: Paraíba, Sergipe, Alagoas e Piauí, conforme os dados do gráfico 1.

Ademais, observou-se também a origem das pessoas que solicitam refúgio no Brasil, considerando o mesmo recorte temporal (de 2015 a 2020) e verificou-se que estas são oriundas dos seguintes países: Cuba, Venezuela, Guiné-Bissau, Senegal, Haiti, China, Filipinas, Bangladesh, Angola.

Ao correlacionar o período da pandemia com as solicitações de refúgio, percebe-se que, de acordo com os dados do Comitê para Refugiados (CONARE), houve uma redução significativa em todo o Brasil. Nesse cenário, a região Nordeste recebeu tão somente 89 solicitações de refúgio no período de janeiro a maio de 2020, em sua grande maioria, os solicitantes são vindos de Cuba, Venezuela e GuinéBissau.

Essa diminuição é incumbida ao fato de que, com o surgimento da pandemia, a mobilidade humana por meio do refúgio ganhou um novo obstáculo, afinal os países estão com suas fronteiras fechadas por questões de saúde e sanitárias e, apesar disso não impedir legislativamente que existam as solicitações de refúgio, tal fator dificulta de forma considerável a realização destas. No caso do Brasil, desde março de 2020, o governo brasileiro, por meio das Portarias $n^{\circ}$ 47 e $\mathrm{n}^{\circ} 255$, tomou decisões no sentido de proibir a entrega de imigrantes em detrimento do avanço da pandemia no Brasil. Inclusive, a Portaria $n^{\circ} 255$ proíbe expressamente a entrada de qualquer estrangeiro no país. Com isso, tem-se dificultado o acolhimento aos refugiados.

Compreende-se, então, a necessidade do papel do Estado na efetivação de políticas públicas para garantir os Direitos dos refugiados, pois, apesar da garantia legal, eles ainda enfrentam dificuldades no Brasil, principalmente, diante de situações como a da pandemia ocasionada 
pela COVID-19, que se configura como uma condição agravadora da vulnerabilidade dos refugiados.

Data de Submissão: 30/07/2020

Data de Aprovação: 19/03/2021

Processo de Avaliação: double blind peer review

Editor Geral: Jailton Macena de Araújo

Editor de Área: Jailton Macena de Araújo

Assistente Editorial: Jaqueline Rosário Santana

\section{REFERÊNCIAS}

ACESSO aos serviços de saúde é essencial para conter a COVID-19 e salvar vidas de refugiados. Portal ACNUR Brasil, 31 mar. 2020. Disponível em:

https://www.acnur.org/portugues/2020/o3/31/acesso-aos-servicosde-saude-e-essencial-para-conter-a-covid-19-e-salvar-vidas-derefugiados/. Acesso em: 11 maio 2020.

AGÊNCIAS da ONU pedem proteção de refugiados e deslocados contra covid-19. ONU NEWS, Migrantes e refugiados. 1 abr. 2020. Disponível em: https://news.un.org/pt/story/2020/04/1709072. Acesso em: 11 maio 2020.

\section{ALTO COMISSARIADO DAS NAÇÕES UNIDAS PARA OS} REFUGIADOS (ACNUR). Cinco (5) motivos para não esquecer os refugiados na luta contra a COVID-19. 26 mar. 2020. Disponível em: https://www.acnur.org/portugues/2020/03/26/5-motivos-paranao-esquecer-os-refugiados-na-luta-contra-a-covid-19/. Acesso em: 10 maio 2020. 
Mobilidade E Pandemia: Análise Da Vulnerabilidade Dos Refugiados Diante Da...

Refugiados. Disponível em:

https://www.acnur.org/fileadmin/Documentos/portugues/BDL/Con vencao_relativa_ao_Estatuto_dos_Refugiados.pdf. Acesso: 10 maio 2020.

ALTO COMISSARIADO DAS NAÇÕES UNIDAS PARA OS REFUGIADOS (ACNUR). Histórico. 2020. Disponível em: https://www.acnur.org/portugues/historico/\#: :text=O\%20escrit\% C3\%B3rio\%20do\%20Alto\%20Comissariado,fugiram\%20ou\%20perd eram\%20suas\%20casas.\&text=Em\%201995\%2C\%20a\%20Assemblei a\%20Geral,ap\%C3\%A1tridas\%20em\%20todo\%200\%20mundo.

Acesso em: 10 maio 2020.

ALTO COMISSARIADO DAS NAÇÕES UNIDAS PARA OS REFUGIADOS (ACNUR). Relatório global do ACNUR revela deslocamento forçado de 1\% da humanidade. Portal ACNUR Brasil, Genebra, 18 jun. 2020. Disponível em:

https://www.acnur.org/portugues/2020/o6/18/relatorio-global-doacnur-revela-deslocamento-forcado-de-1-da-humanidade/. Acesso em:18 jun. 2020.

BRASIL. [Constituição (1988)]. Constituição da República

Federativa do Brasil. Brasília, DF: Senado, 1988. Disponível em: http://www.planalto.gov.br/ccivil_03/constituicao/constituicao.htm . Acesso em: 27 out. 2020.

BRASIL. Lei n. ${ }^{\circ}$ 9.474, de 22 de julho de 1997. Define mecanismos para implementação do Estatuto dos Refugiados de 1951, e determina outras providencias. Diário Oficial da União, Brasília, DF, 23 jul. 1997. Disponível em:

http://www.planalto.gov.br/ccivil_03/LEIS/L9474.htm. Acesso: 10 maio 2020.

BRASIL. Lei no 13.445, de 24 de maio de 2017. Institui a Lei de Migração. Diário Oficial da União, Brasília, DF, 25 mai. 2017. Disponível em: http://www.planalto.gov.br/ccivil_03/_ato20152018/2017/lei/l13445.htm. Acesso: 11 maio 2020.

BRASIL. Lei no 13.982, de 2 de abril de 2020. Diário Oficial da União, Brasília, DF, 2 abr. 2020. Disponível em: http://www.planalto.gov.br/ccivil_03/_ato20192022/2020/lei/l13982.htm. Acesso: 11 maio 2020.

BRASIL. Presidência da República/Casa Civil. Portaria nº 47, de 26 de março de 2020. Diário Oficial da União, Brasília, DF, 26 mar. 2020. Disponível em: http://www.in.gov.br/en/web/dou/-/portarian-47-de-26-de-marco-de-2020-249861855 Acesso em: 25 jun. 2020.

BRASIL. Presidência da República/Casa Civil. Portaria no 255, de 22 de maio de 2020. Diário Oficial da União, Brasília, DF, 22 mai. 
2020. Disponível em: http://www.in.gov.br/en/web/dou/-/portarian-255-de-22-de-maio-de-2020-258114133 Acesso em: 25 jun. 2020

CARVALHO, Michael. Venezuelanos refugiados no Recife relatam falta de doações na pandemia. Rádio jornal Recife. 2020. Disponível em: https://radiojornal.ne1o.uol.com.br/noticia/2020/04/21/venezuela nos-refugiados-no-recife-relatam-falta-de-doacoes-na-pandemia187414. Acesso em: 10 maio 2020.

CECATO, M. ÁUREA B.; OLIVEIRA, A. A. DE. Direitos Sociais: do Estado Liberal ao Estado Social. Prim@ Facie, v. 15, n. 29, p. 01-25, 8 mar. 2017. Disponível em:

https://periodicos.ufpb.br/ojs2/index.php/primafacie/article/view/ 33120. Acesso em 23 nov. 2020.

CORONAVÍRUS e refugiados: o que o ACNUR está fazendo no Brasil e no mundo. Portal ACNUR Brasil, 27 mar. 2020. Disponível em: https://www.acnur.org/portugues/2020/o3/27/coronavirus-erefugiados-o-que-o-acnur-esta-fazendo-no-brasil-e-no-mundo/. Acesso em: 10 maio 2020.

COSTA, Érica Nadir M. de Vasconcelos; PEIXOTO, Arnelle Rolim. O processo de integração dos refugiados através da educação: um estudo de caso na cidade de Fortaleza. In: ANNONI, Danielle (coord.). Direito Internacional dos Refugiados e o Brasil. Curitiba: Gedai/UFPR, 2018, p. 517 - 535.

DUMONT, Gérard-François. Covid-19: fim da geografia da hipermobilidade? Espaço e Economia [Online], 18, 2020, posto online no dia 20 abril 2020. Disponível em:

http://journals.openedition.org/espacoeconomia/12926. Acesso em: 30 maio 2020.

GRANDI, Filippo. The coronavirus outbreak is a test of our systems, values and humanity. The Telegraph, 10 mar. 2020. Disponível em: https://www.telegraph.co.uk/global-health/science-anddisease/coronavirus-outbreak-test-systems-values-humanity/. Acesso em: 11 maio 2020.

KURZ, Robert. Não há Leviatã que vos salve: Teses para uma teoria crítica do Estado. EXIT!

Crise e Crítica da Sociedade da Mercadoria, n. 7, dezembro de 2010 (tradução de Boaventura Antunes e Lumir Nahodil). Disponível em: http://www.obeco-online.org/rkurz39o.htm Acesso em: 25 nov. 2020.

MACENA DIAS DE OLIVEIRA, M. DAS G.; CARMO, V. M. DO; BASTOS DE OLIVEIRA, B. Sistema Interamericano De Proteção Dos Diretos Humanos: Análise Da Efetividade No Brasil. Prim@ Facie, 
Mobilidade E Pandemia: Análise Da Vulnerabilidade Dos Refugiados Diante Da...

v. 18, n. 39, p. 01-33, 31 dez. 2019. Disponível em:

https://periodicos.ufpb.br/index.php/primafacie/issue/view/2436.

Acesso em 23 nov. 2020.

ORGANIZAÇÃO PANAMERICANA DE SAÚDE (OPAS). Folha informativa - COVID-19 (doença causada pelo novo coronavírus). 2020. Disponível em:

https://www.paho.org/bra/index.php?option=com_content\&view=a rticle\&id=6101: covid19\&Itemid=875. Acesso em: 11 maio 2020.

ORGANIZAÇÃO PANAMERICANA DE SAÚDE (OPAS).

Preparação, prevenção e controle da doença do coronavírus (COVID-19) para refugiados e migrantes em ambientes fora dos campos de refugiados. Orientação provisória. 2020. Disponível em:

https://iris.paho.org/handle/10665.2/52456. Acesso em: 18 jun. 2020.

RAMOS, André de Carvalho. Asilo e Refúgio: semelhanças, diferenças e perspectivas. In: RAMOS, André de Carvalho; RODRIGUES, Gilberto; ALMEIDA, Guilherme Assis de (orgs). 60 anos de ACNUR: perspectivas de futuro. São Paulo: CLA Cultura, 2011, p. 15-44

RIBEIRO, Jullyane Carvalho. Construindo refugiados: reflexões sobre gênero e outras categorias de diferenciação na elegibilidade e na administração do refúgio no Brasil. In: LUSSI, Carmem (org.). Migrações Internacionais. Abordagens de Direitos Humanos. Brasília: Centro Scalabriniano de Estudos Migratórios, 2017, p. 235250.

RODRIGUES, Igor de Assis; CAVALCANTE João Roberto; FAERSTEIN, Eduardo. Pandemia de Covid-19 e a saúde dos refugiados no Brasil. Physis: Revista de Saúde Coletiva, Rio de Janeiro, v. 30(3), e.300306, 2020. Disponível em:

https://preprints.scielo.org/index.php/scielo/preprint/view/997 Acesso em: 23 nov. 2020.

SOUSA, Viviane. Com pandemia de Covid-1, solicitações de refúgio despencam no Brasil em 2020. Portal G1, 20 jun. 2020. Disponível em: https://g1.globo.com/mundo/noticia/2020/o6/20/compandemia-de-covid-19-solicitacoes-de-refugio-despencam-no-brasilem-2020.ghtml. Acesso em: 25 jun. 2020.

SOUZA, Paulo Nonato de. Quer saber onde a Pandemia do coronavírus não chegou? Campo Grande News, Lugares por Onde Ando, 27 jun. 2020. Disponível em:

https://www.campograndenews.com.br/turismo/quer-saber-onde-apandemia-do-coronavirus-nao-chegou. Acesso em: 24 jul. 2020. 


\title{
Mobility And Pandemia: Analysis Of Refugee Vulnerability In Front Of Covid-19 In Northeast Brazil
}

\author{
Arnelle Rolim Peixoto
}

\author{
Kananda Beatriz Pinto de Sena
}

\author{
Camilla Martins Cavalcanti
}

\begin{abstract}
In the COVID-19 pandemic, there are many challenges regarding human mobility flows. In this sense, the objective is to analyze international mobility of refugees in northeastern Brazil in the face of the pandemic and the possible increase in the vulnerability of migrant subjects in the face of this situation. The article is structured in three stages. Initially, the protective apparatus (national and international) concerning refugees was shown. Then, the challenge of welcoming refugees and the possibility of accentuated characterization of their vulnerability due to the COVID-19 pandemic were analyzed, and for that purpose, data from the Ministry of Justice, in particular from the National Committee for Refugees (CONARE), the United Nations High Commissioner for Refugees (UNHCR), and also the Ministry of Health. Finally, the need for instruments / means to guarantee the protection of refugees in situations of aggravating risk is explained, especially, in the face of the facts and consequences of the COVID-19 pandemic. The research used a bibliographic methodology, of a qualitative nature, with descriptive and exploratory purposes. It was concluded that the COVID-19 pandemic is a configurator of the double vulnerability of the population in a situation of refuge, and, thus, there is the emergence of new regulatory frameworks and instruments that enable the protection of refugees.
\end{abstract}

Keywords: Refuge. Coronavirus. Northeast Brazil.

DOI: https://doi.org/10.22478/ufpb.1678-2593.2021v20n43.54239

Conteúdo sob licença Creative Commons: Attribuition-NonCommercial-NoDerivative 4.o International (CC BY-NC-ND 4.0) 